\title{
Analisis Sensitivitas Model Matematika Penyebaran Penyakit dengan Vaksinasi
}

\author{
Fourianita Y. Malorung, Megawati A. Blegur, \\ Rapmaida M. Pangaribuan, Meksianis Z. Ndi** \\ Jurusan Matematika Fakultas Sains dan Teknik \\ Universitas Nusa Cendana \\ meksianis.ndii@staf.undana.ac.id
}

\begin{abstract}
Abstrak
Pemodelan matematika telah banyak digunakan untuk menganalisis dinamika penyebaran dan tingkat keefektifan strategi pencegahan penyakit. Penelitian ini fokus pada analisis model epidemi Susceptible-Infected-Recovered (SIR) dengan vaksinasi random dan model Susceptible-Vaccinated-Infected-Recovered (SVIR) pada saat lahir. Analisis sensitivitas dilakukan untuk mengetahui parameter yang berpengaruh pada jumlah individu terinfeksi dan ambang batas epidemik (basic reproduction number). Hasil penelitian menunjukkan bahwa pada model SIR, laju penularan $(\beta)$ dan laju kesembuhan $(\gamma)$ merupakan parameter yang paling berpengaruh terhadap basic reproduction number. Laju kelahiran dan kematian $(\mu)$, tingkat keefektifan vaksin $(p)$ dan laju kesembuhan $(\gamma)$ merupakan parameter yang berpengaruh pada titik tetap infected. Untuk model SVIR, laju penularan $(\beta)$ dan laju kesembuhan $(\gamma)$ merupakan parameter yang berpengaruh pada basic reproduction number, sedangkan laju kelahiran dan kematian $(\mu)$ dan laju kesemb $\gamma$ an $\gamma$ merupakan parameter yang berpengaruh pada titik tetap infected.

Kata kunci: Model SIR, Model SVIR, Bilangan Reproduksi Dasar, Analisis Sensitivitas.
\end{abstract}

\begin{abstract}
Mathematical model has been used to analyse the disease transmission dynamics and the efficacy of the eradication strategies against the diseases. We study SIR model with random vaccination and SVIR model with vaccination at birth. We analyse the sensitivity of the parameters on the basic reproduction number and the infected population. The results showed that for both models the transmission rate ( $\beta$ ) and the recovery rate are the most influential parameters on the basic reproduction number. Furthermore, the vaccince efficacy ( $p)$ and the recovery rate $(\gamma)$ are the most influential parameters on the infected equilibrium. Keywords : SIR Model, SVIR Model, Basic Reproduction Numbers, Sensitivity Analysis.
\end{abstract}

2000 Mathematics Subject Classification: 92B05;34B60

Received: 2018-03-06, accepted: 2018-04-17.

* Corresponding Author. 


\section{Pendahuluan}

Pemodelan matematika telah banyak digunakan untuk mengidentifikasi dan menganalisis dinamika penyebaran penyakit $[1,2]$ termasuk untuk menganalisis keefektifan suatu intervensi kesehatan seperti keefektifan bakteri Wolbachia $[3,4]$ atau vaksinasi $[5,6]$. Pada umumnya, model matematika penyebaran penyakit diformulasi dalam bentuk model matematika deterministik [7] atau stokastik [8].

Salah satu tantangan dalam menganalisis dinamika penyebaran penyakit atau keefektifan sebuah intervensi kesehatan dengan menggunakan model matematika adalah kesensitifan dari parameter terhadap hasil dari model matematika. Hal tersebut berpengaruh pada keakuratan prediksi atau hasil dari model matematika tersebut. Oleh karena itu, dalam menganalisis dinamika atau keefektifan intervensi kesehatan dengan menggunakan model matematika diperlukan analisis sensitivitas untuk mengetahui parameter yang paling berpengaruh pada model matematika $[9,10]$. Informasi ini penting dan berguna dalam tahap estimasi parameter, interpretasi hasil penelitian atau pencarian kemungkinan-kemungkinan solusi jika nilai parameter tersebut berubah.

Salah satu intervensi kesehatan yang paling banyak digunakan untuk mengatasi penyebaran suatu penyakit menular adalah vaksinasi [11]. Periode vaksinasi berbeda untuk tiap jenis penyakit. Sebagai contoh, Pemberian vaksin campak dilakukan pada individu berumur 9 bulan, 15 bulan, 6 tahun. Pemberian vaksin demam berdarah pada umur 9-45 tahun akan lebih efektif [5]. Secara umum, vaksinasi dapat dilakukan pada saat lahir atau secara random beberapa kurun waktu tertentu setelah lahir. Penelitian ini fokus pada analisis sensitivitas model epidemi terhadap basic reproduction number (ambang batas epidemik) dan titik tetap infected. Secara khusus, penelitian ini untuk mengetahui parameter yang paling berpengaruh terhadap basic reproduction number dan titik tetap infected dari model epidemi dengan vaksinasi secara acak dan pada saat lahir.

\section{MODEL MATEMATIKA SIR DENGAN VAKSINASI SECARA RANDOM}

Pada bagian ini akan diberikan model matematika dengan vaksinasi pada saat lahir dan secara acak. Model-model matematika seperti ini banyak ditemukan pada literatur [7, 12]. Diagram alir untuk model matematika dengan vaksinasi secara acak diberikan pada Gambar 1 dan pada saat lahir diberikan pada Gambar 2. Beberapa asumsi umum yang digunakan dalam model matematika adalah sebagai berikut. Pertama, jumlah populasi diasumsikan konstan. Ini berarti bahwa laju kelahiran dan laju kematian diasumsikan sama. Kedua, pada model dengan vaksinasi acak/random, vaksinasi diasumsikan menurunkan laju transmisi penyakit. Ketiga, pada model dengan vaksinasi pada saat lahir, diasumsikan bahwa individu yang baru lahir langsung di berikan vaksin.

2.1. Formulasi Model Matematika. Pada bagian ini akan dipaparkan model epidemi dengan vaksinasi secara acak. Vaksinasi diasumsikan menurunkan laju transmisi penyakit dan tingkat keefektifan vaksin dinotasikan dengan parameter $p$. Diagram alir dari model tersebut diberikan pada Gambar 1.

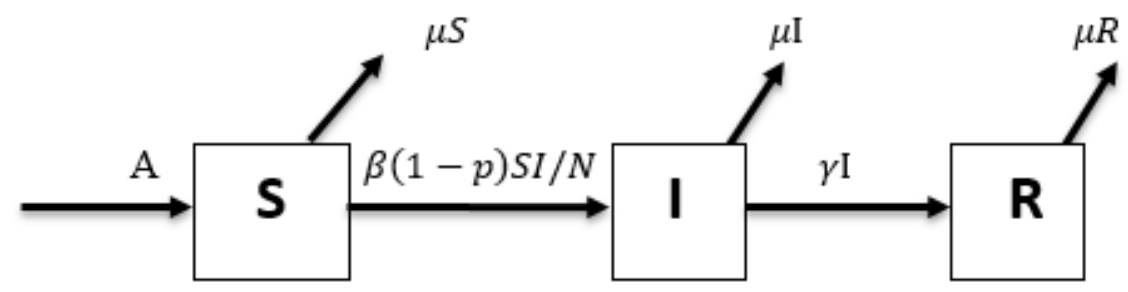

Gambar 1. Diagram alir model matematika dengan vaksinasi secara random. Vaksinasi diasumsikan menurunkan laju transmisi penyakit. 
Model matematika SIR dengan vaksinasi secara acak diberikan oleh persamaan berikut :

$$
\begin{aligned}
\frac{d S}{d t} & =A-\frac{\beta(1-p) S I}{N}-\mu S, \\
\frac{d I}{d t} & =\frac{\beta(1-p) S I}{N}-\gamma I-\mu I, \\
\frac{d R}{d t} & =\gamma I-\mu R
\end{aligned}
$$

dimana A adalah $\mu N$, parameter $\beta$ adalah laju transmisi, $p$ adalah tingkat efektifitas vaksin, $\gamma$ adalah laju kesembuhan dan $\mu$ adalah laju kematian alami. Pada model ini, jumlah populasi diasumsikan konstan. Dari Model (1) terlihat bahwa pemberian vaksin mengurangi force of infection (FoI). FoI akan semakin kecil apabila nilai atau tingkat keefektifan vaksin mendekati nilai satu.

2.2. Analisis Sensitivitas. Pada bagian ini akan dibahas titik tetap, basic reproduction number,dan analisis sensitivitas. Dengan membuat ruas kanan dari Model (1) menjadi nol dan melakukan manipulasi aljabar maka diperoleh dua titik kesetimbangan yakni titik bebas penyakit, $E_{0}$, dan titik endemik, $E_{e}$, sebagai berikut $E_{0}=\left(S^{*}, I^{*}, R^{*}\right)=\left(\frac{A}{\mu}, 0,0\right)$ dan $E_{e}=\left(S^{*}, I^{*}, R^{*}\right)$ dimana

$$
S^{*}=-\frac{N(\gamma+\mu)}{\beta(-1+p)} I=\frac{A \beta p-N \gamma \mu+N \mu^{2}-A \beta}{\beta(\gamma p+\mu p-\gamma-\mu)} R=\frac{\gamma\left(A \beta p+N \gamma \mu+N \mu^{2}-A \beta\right)}{\beta(\gamma p+\mu p-\gamma-\mu) \mu} .
$$

Dengan mengonstruksi the next generation matrix [13], diperoleh basic reproduction number yakni

$$
R_{0}=\frac{\beta(1-p)}{\gamma+\mu} .
$$

2.3. Analisis Sensitivitas Terhadap basic reproduction number $\left(R_{0}\right)$. Analisis sensitivitas yang dilakukan pada penelitian ini adalah analisis sensitivitas lokal [10,14]. Definisi indeks sensitivitas dapat dilihat pada Definisi 2.2.1. Perlu dicatat bahwa jika nilai indeks sensitivitasnya semakin besar, maka parameter tersebut merupakan parameter yang paling berpengaruh. Tanda positif dan negatif menunjukkan hubungan antara parameter tersebut dengan variabel yang dianalisis yakni basic reproduction number dan titik tetap infected.

Definisi 2.1. Normalized sensitivity index diperoleh dengan indeks sensitivitas normalisasi dari variabel $V$, terdiferensialkan pada parameter $p$, didefinisikan sebagai berikut:

$$
C_{p}^{v}=\frac{\partial V}{\partial p} \times \frac{p}{V}
$$

dimana $V$ adalah variabel yang akan dianalisis dan $p$ adalah parameter [14].

Definisi diatas berarti bahwa indeks sensitivitas dicari dengan menggunakan konsep laju perubahan yang kemudian diukur besar kecilnya perubahan tersebut. Semakin besar indeks tersebut maka semakin besar pengaruh parameter tersebut terhadap variabel yang diukur. Pada bagian ini akan dilakukan analisis sensitivitas parameter terhadap basic reproduction number. Indeks sensitivitas dari parameter $\beta$ adalah

$$
C_{\beta}^{R_{0}}=\frac{d R_{0}}{d \beta} \times \frac{\beta}{R_{0}}=\frac{1-p}{\gamma+\mu} \times \frac{\beta(\gamma+\mu)}{\beta(1-p)}=1
$$

Dengan prosedur yang sama diperoleh ekspresi sensitivitas untuk parameter lainnya. Tabel 1. Ekspresi Sensitivitas Parameter Terhadap Basic Reproduction Number $\left(R_{0}\right)$. Nilai parameter yang digunakan adalah $\beta=0,5, \gamma=1 / 21, p=0,67$, dan $\mu=1 /(70 \times 365)$. 
Tabel 1. Ekspresi Sensitivitas Parameter Terhadap Basic Reproduction Number $\left(R_{0}\right)$.

\begin{tabular}{|c|c|c|c|c|}
\hline Parameter & Ekspresi Sensitivitas & Nilai & \multicolumn{2}{|c|}{$R_{0}=3.4521$} \\
\hline & & & $\mathrm{P}-10 \%$ & $\mathrm{P}-10 \%$ \\
\hline$\beta$ & 1 & 1 & 3.1159 & 3.8083 \\
\hline$\mu$ & $-\frac{\mu}{(\gamma+\mu)}$ & -0.00082 & 3.46243 & 3.4618 \\
\hline$\gamma$ & $-\frac{\gamma}{(\gamma+\mu)}$ & -0.99917 & 3.8464 & 3.1476 \\
\hline$p$ & $\mathrm{p}-1$ & -0.33 & 4.1965 & 2.83326 \\
\hline \multicolumn{4}{|r|}{} \\
\hline
\end{tabular}

Dari hasil indeks sensitivitas (lihat Tabel 1) terlihat bahwa parameter yang paling berpengaruh atau sensitif terhadap $R_{0}$ adalah laju penularan $(\beta)$ dan laju kesembuhan $(\gamma)$. Adapun parameter $\beta$ memiliki hubungan positif dan parameter memiliki hubungan negatif terhadap $R_{0}$. Untuk menguji apakah hubungan antara parameter dan basic reproduction number sesuai, maka dilakukan perubahan nilai parameter sebesar $10 \%$ baik itu ditambah atau dikurangai untuk melihat nilai basic reproduction number nya. Terlihat bahwa jika nilai parameter $\beta$ ditambah $10 \%$ maka nilai $R_{0}$ naik dari 3,4621 menjadi 3,8083 . Sebaliknya, jika nilai parameter $\beta$ dikurangi $10 \%$ maka nilai $R_{0}$ juga turun. Ini membuktikan bahwa hasil analisis sejalan dengan hasil ujicoba pada nilai $R_{0}$.

2.4. Analisis sensitivitas terhadap titik infected $\left(I^{*}\right)$. Analisis sensitivitas terhadap $I^{*}$ dilakukan untuk mengetahui parameter-parameter manakah yang paling berpengaruh terhadap $I^{*}$. Parameter-parameter yang akan dianalisis adalah $\beta, \gamma, p, \mu$. Dengan prosedur yang sama mengikuti definisi 2.1. maka diperoleh hasil indeks sensitivitas dari parameter terhadap titik tetap infected dan hasilnya disajikan pada Tabel 2 .

Tabel 2. Indeks Sensitivitas dari Parameter terhadap Titik Tetap Infected.

\begin{tabular}{|c|c|c|c|c|}
\hline Parameter & Ekspresi Sensitivitas & Nilai & \multicolumn{2}{|c|}{$I^{*}=5,8403$} \\
\hline & & & $\mathrm{P}-10 \%$ & $\mathrm{P}-10 \%$ \\
\hline$\beta$ & $\frac{\beta(p-1)}{(\beta p+\gamma+\mu-\beta)}-1$ & +0.4061 & 5.5768 & 6.0560 \\
\hline$\mu$ & $-\frac{\beta p+\gamma+2 \mu-\beta)}{(\beta p+\gamma+\mu-\beta)}-\frac{\mu}{\gamma+\mu}$ & +0.998 & 5.2569 & 6.4236 \\
\hline$\gamma$ & $-\frac{\gamma}{(\beta p+\gamma+\mu-\beta)}-\frac{\gamma}{\gamma-\mu}$ & -0.9054 & 6.7520 & 5.0943 \\
\hline$p$ & $\frac{\beta p}{\beta p+\gamma+\mu-\beta}-\frac{(p \gamma+\mu p)}{\gamma p+\mu p-\gamma-\mu}$ & -0.8246 & 6.2554 & 5.3131 \\
\hline
\end{tabular}

Dari Tabel 2 terlihat bahwa parameter yang paling berpengaruh terhadap titik tetap infected adalah parameter $\mu, p$, dan $\gamma$ dimana parameter $\mathrm{p}$ dan $\gamma$ memiliki hubungan yang negatif sedangkan parameter $\mu$ memiliki hubungan positif. Ini berarti bahwa ketika nilai parameter $\mathrm{p}$ dan $\gamma$ naik, maka jumlah individu terinfeksi akan menurun, dan sebaliknya. Hal tersebut terlihat dari jumlah individu terinfeksi jika nilai parameter mengalami kenaikan atau penurunan sebesar $10 \%$.

\section{MODEL MATEMATIKA DENGAN VAKSINASI SAAT LAHIR}

Pada bagian ini akan dipaparkan model matematika dengan vaksinasi pada saat lahir dan juga analisis sensitivitasnya.

3.1. Formulasi Model Matematika. Pada bagian ini akan paparkan model matematika dengan vaksinasi pada saat lahir. Model matematika dengan vaksinasi pada saat lahir diberikan pada Gambar 2. 


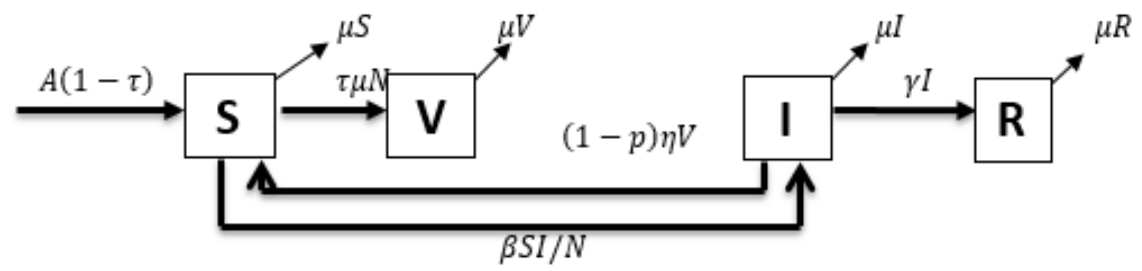

Gambar 2. Diagram Alir Model Matematika dengan Vaksinasi Pada saat Lahir.

Model matematika dibentuk dari sistem persamaan diferensial nonlinear berikut.

$$
\begin{gathered}
\frac{d S}{d t}=\mu N(1-\tau)-\beta S \frac{1}{N}+(1-p) \eta V-\mu S, \\
\frac{d V}{d t}=\tau \mu N-(1-p) \eta V-\mu V, \\
\frac{d I}{d t}=\beta S \frac{1}{N}-\mu I-\gamma I, \\
\frac{d I}{d t}=\gamma I-\mu R,
\end{gathered}
$$

dimana $\mathrm{N}$ adalah populasi total, $\beta$ adalah laju penularan, $p$ adalah tingkat keefektifan vaksin, $\eta$ adalah rata-rata individu yang kehilangan imunitas dan $\gamma$ adalah laju kesembuhan.

3.2. Analisis Sensitivitas. Pada bagian ini akan dibahas titik kesetimbangan, basic reproduction number dan analisis sensitivitas. Titik tetap diperoleh dengan membuat ruas kanan sama dengan nol kemudian dilakukan manipulasi aljabar dan diperoleh titik tetap bebas penyakit $\left(\frac{(N(\eta p+\mu \tau-\eta-\mu))}{(\eta p-\eta-\mu)}, \frac{\tau \mu N}{(1-p) \eta+\mu}, 0,0\right)$ dan titik tetap endemik $E_{1}=\left(S^{*}, V^{*}, I^{*}, R^{*}\right)$ dimana

$$
\begin{gathered}
S^{*}=\frac{(\mu+\gamma)}{\beta} \\
V^{*}=-\frac{\tau \mu N}{\eta p-\eta-\mu} \\
I^{*}=-\frac{\mu N\left(-\beta \eta p-\mu \beta \tau+\mu \eta p+\gamma \eta p+\eta \beta+\mu \beta-\mu \eta-\gamma \eta-\gamma \mu-\mu^{2}\right)}{\beta\left(\mu \eta p+\gamma \eta p-\mu \eta-\gamma \eta-\gamma \mu-\mu^{2}\right)} \\
R^{*}=-\frac{N \gamma\left(-\beta \eta p-\mu \beta \tau+\mu \eta p+\gamma \eta p+\eta \beta+\mu \beta-\mu \eta-\gamma \eta-\gamma \mu-\mu^{2}\right)}{\beta\left(\mu \eta p+\gamma \eta p-\mu \eta-\gamma \eta-\gamma \mu-\mu^{2}\right.}
\end{gathered}
$$

Dengan mengonstruksi the next generation matrix dan mencari nilai eigen terbesar [13] diperoleh basic reproduction number nya adalah

$$
R_{0}=\frac{\beta(\eta p+\mu \tau-\eta-\mu)}{\left(\eta p \gamma+\mu \eta p-\eta \gamma-\gamma \mu-\mu \eta-\mu^{2}\right)}
$$

3.3. Analisis Sensitivitas terhadap Basic Reproduction Number $\left(R_{0}\right)$ dan Titik Tetap Infected $\left(I^{*}\right)$. Pada bagian ini akan dilakukan analisis sensitivitas parameter terhadap basic reproduction number dan titik tetap infected. Dengan prosedur yang sama sebagaimana pada model SIR maka diperoleh indeks sensitivitas sebagaimana diberikan pada Tabel 3. 
Tabel 3 Indeks sensivitas parameter terhadap basic reproduction number.

\begin{tabular}{|c|c|c|c|c|}
\hline Parameter & Ekspresi Sensitivitas & Nilai & \multicolumn{2}{c|}{$R_{0}=10,49$} \\
\hline & 1 & & $\mathrm{P}-10 \%$ & $\mathrm{P}-10 \%$ \\
\hline$\beta$ & $\frac{(\beta p-\beta) \eta}{\beta \eta p+\mu \tau \beta-\beta \eta-\beta \mu}-\frac{(p \gamma-\mu p-\gamma-\mu) \eta}{\left(\eta p \gamma+\eta p \mu-\gamma \mu-\mu \eta-\mu \gamma-\mu^{2}\right)}$ & 0.0001 & 10.4903 & 10.4909 \\
\hline$\eta$ & $\frac{\beta \eta p}{\beta \eta p+\mu \tau \beta-\beta \eta-\beta \mu}-\frac{(\eta \gamma+\eta \mu) p}{\left(\eta p \gamma+\eta p \mu-\gamma \mu-\mu \eta-\mu \gamma-\mu^{2}\right)}$ & -0.5610 & 10.489 & 10.49042 \\
\hline$p$ & $\frac{\tau+\mu \beta}{\beta \eta p+\mu \tau \beta-\beta \eta-\beta \mu}$ & -0.0001 & 10.49009 & 10.4903 \\
\hline$\tau$ & $-\frac{-\eta p \gamma+\eta \gamma+\mu \gamma}{\eta p \gamma+\eta p \mu-\gamma \eta-\mu \eta-\mu \gamma}$ & -0.9991 & 9.0834 & 11.1002 \\
\hline$\gamma$ & & & & \\
\hline
\end{tabular}

Dari Tabel 3 dapat diketahui bahwa parameter yang paling berpengaruh terhadap $R_{0}$ adalah parameter $\beta, \gamma$ dan parameter p. Hal ini dapat diketahui dari nilai hasil substitusi nilai parameter terhadap ekspresi sensitivitas masing-masing parameter dan dari nilai tersebut juga dapat diketahui hubungan antara masing-masing parameter terhadap $R_{0}$. Adapun hubungan parameter-parameter di atas terhadap $R_{0}$ yaitu parameter $\beta$ memiliki hubungan positif terhadap $R_{0}$ artinya ketika nilai parameter ditambah maka $R_{0}$ akan naik sebaliknya ketika nilai parameter dikurangi maka $R_{0}$ akan turun dan parameter $\gamma, p$ memiliki hubungan negatif terhadap $R_{0}$ artinya ketika nilai parameter ditambah maka $R_{0}$ akan turun demikian sebaliknya.

Dengan prosedur yang sama untuk mencari ekspresi sensitivitas parameter terhadap titik endemik akan diperoleh bahwa parameter $\mu$ dan $\gamma$ adalah parameter yang sangat berpengaruh terhadap kenaikan jumlah individu terinfeksi. Parameter $\gamma$ memiliki hubungan yang negatif sedangkan parameter $\mu$ memiliki hubungan yang positif terhadap kenaikan jumlah individu terinfeksi.

\section{Simpulan}

Hasil analisis sensitivitas menunjukkan bahwa pada model SIR, laju penularan $(\beta)$ dan laju kesembuhan $(\gamma)$ merupakan parameter yang paling berpengaruh terhadap basic reproduction number sedangkan laju kelahiran dan kematian $(\mu)$, tingkat keefektifan vaksin $(\mathrm{p})$ dan laju kesembuhan $(\gamma)$ merupakan parameter yang berpengaruh pada titik tetap infected. Pada model SVIR, laju penularan $(\beta)$ dan laju kesembuhan $(\gamma)$ merupakan parameter yang berpengaruh pada basic reproduction number, sedangkan laju kelahiran dan kematian $(\mu)$ dan laju kesembuhan $(\gamma)$ merupakan parameter yang berpengaruh pada titik tetap infected.

\section{Daftar Pustaka}

[1] Ndii, M.Z., Mathematical Modelling to Investigate a Wolbachia intervention to reduce dengue transmission, in Department of Mathematics. 2015, University of Newcastle.

[2] Supriatna, A.K., E. Soewono, and S.A. van Gils, A two-age-classes dengue transmission model. Mathematical Biosciences, 2008. 216(1): p. 114-121.

[3] Ndii, M.Z., et al., The effect of Wolbachia on dengue dynamics in the presence of two serotypes of dengue: symmetric and asymmetric epidemiological characteristics. Epidemiology and Infection, 2016. 144(13): p 2874-2882.

[4] Ndii, M.Z., et al., The effect of Wolbachia on dengue outbreaks when dengue is repeatedly introduced. Theoretical Population Biology, 2016. 111: p. 9-15.

[5] Dorigatti, I., et al., Modelling the immunological response to a tetravalent dengue vaccine from multiple phase-2 trials in Latin America and South East Asia. Vaccine, 2015. 33(31): p. 3746-3751.

[6] Ferguson, N.M., et al., Benefits and risks of the Sanofi-Pasteur dengue vaccine: Modeling optimal deployment. Science, 2016. 353(6303): p. 1033-1036.

[7] de Vries, G., et al., A Course in Mathematical Biology: Quantitative Modeling with Mathematical and Computational Methods. 2006: Society for Industrial and Applied Mathematics. 
[8] Ndii, M.Z. and A.K. Supriatna, Stochastic Mathematical Models in Epidemiology. Information, 2017. 20: p. 6185-6196.

[9] Marino, S., et al., A methodology for performing global uncertainty and sensitivity analysis in systems biology. Journal of Theoretical Biology, 2008. 254(1): p. 178-196.

[10] Hurint, R.U., M.Z. Ndii, and M. Lobo, Analisis Sensitivitas Model Epidemi SEIR. Natural Science: Journal of Science and Technology, 2017. 6(1): p. 22-28.

[11] Malorung, F., Analisis Dinamika Transmisi Virus Rubella Dengan Vaksinasi, in Jurusan Matematika, Universitas Nusa Cendana. 2017, Jurusan Matematika, Universitas Nusa Cendana.

[12] Keeling, M.J. and P. Rohani, Modeling Infectious Diseases in Humans and Animals. 2007: Princeton University Press.

[13] Diekmann, O., J.A.P. Heesterbeek, and M.G. Roberts, The construction of next-generation matrices for compartmental epidemic models. Journal of The Royal Society Interface, 2009.

[14] Chitnis, N., J.M. Hyman, and J.M. Cushing, Determining Important Parameters in the Spread of Malaria Through the Sensitivity Analysis of a Mathematical Model. Bulletin of Mathematical Biology, 2008. 70(5): p. 1272 . 
16 Malorung et al., JMI Vol.14 No.1 Apr 2018, pp. 9-15,doi:10.24198/jmi.v14.n1.16000.9-15 